\title{
The diagnostic value of biomarkers (SteatoTest) for the prediction of liver steatosis
}

\author{
Thierry Poynard*1, Vlad Ratziu ${ }^{1}$, Sylvie Naveau ${ }^{2}$, Dominique Thabut ${ }^{1}$, \\ Frederic Charlotte ${ }^{3}$, Djamila Messous ${ }^{4}$, Dominique Capron ${ }^{5}$, Annie Abella ${ }^{6}$, \\ Julien Massard ${ }^{1}$, Yen Ngo1, Mona Munteanu ${ }^{7}$, Anne Mercadier ${ }^{8}$, \\ Michael Manns ${ }^{9}$ and Janice Albrecht ${ }^{10}$
}

\begin{abstract}
Address: ${ }^{1}$ Department of Hepato-Gastroenterology, Groupe Hospitalier Pitié-Salpêtrière, Paris, France, ${ }^{2}$ Department of Hepato-Gastroenterology, Hôpital Antoine Béclère, Clamart, France, ${ }^{3}$ Department of Pathology, Groupe Hospitalier Pitié-Salpêtrière, Paris, France, ${ }^{4}$ Department of Biochemistry, Groupe Hospitalier Pitié-Salpêtrière, Paris, France, ${ }^{5}$ Department of Pathology, Hôpital Antoine Béclère, Clamart, France,

${ }^{6}$ Department of Biochemistry, Hôpital Antoine Béclère, Clamart, France, ${ }^{7}$ Biopredictive, Paris, France, ${ }^{8}$ Tranfusion Unit, Groupe Hospitalier PitiéSalpêtrière, Paris, France, ${ }^{9}$ Division of Gastroenterology and Hepatology, Medical School of Hannover, Hannover, Germany and ${ }^{10}$ Schering Plough Research Institute, Kenilworth NJ, USA

Email: Thierry Poynard* - tpoynard@teaser.fr; Vlad Ratziu - vratziu@teaser.fr; Sylvie Naveau - sylvie.naveau@abc.ap-hop-paris.fr; Dominique Thabut - dthabut@libertysurf.fr; Frederic Charlotte - frederic.charlotte@psl.ap-hop-paris.fr; Djamila Messous - djamila.messous@psl.ap-hop-paris.fr; Dominique Capron - frederique.capron@psl.ap-hop-paris.fr;

Annie Abella - annie.abella@abc.ap-hop-paris.fr; Julien Massard - julienmassard@club-internet.fr; Yen Ngo - ngokimphuongyen@yahoo.com; Mona Munteanu - mona.munteanu@biopredictive.com; Anne Mercadier - anne.mercadier@efs.sante.fr; Michael Manns - manns.michael@mhhannover.de; Janice Albrecht - janice.albrecth@spcorp.com

* Corresponding author
\end{abstract}

Published: 23 December 2005

Comparative Hepatology 2005, 4:10 doi:10.1186/1476-5926-4-10
Received: 05 August 2005

Accepted: 23 December 2005

This article is available from: http://www.comparative-hepatology.com/content/4/1/10

(C) 2005 Poynard et al; licensee BioMed Central Ltd.

This is an Open Access article distributed under the terms of the Creative Commons Attribution License (http://creativecommons.org/licenses/by/2.0), which permits unrestricted use, distribution, and reproduction in any medium, provided the original work is properly cited.

\begin{abstract}
Background: Biopsy is the usual gold standard for liver steatosis assessment. The aim of this study was to identify a panel of biomarkers (SteatoTest), with sufficient predictive values, for the non-invasive diagnosis of steatosis in patients with or without chronic liver disease. Biomarkers and panels were assessed in a training group of consecutive patients with chronic hepatitis $C$ and $B$, alcoholic liver disease, and non-alcoholic fatty liver disease, and were validated in two independent groups including a prospective one. Steatosis was blindly assessed by using a previously validated scoring system.
\end{abstract}

Results: 310 patients were included in the training group; 434 in three validation groups; and 140 in a control group. SteatoTest was constructed using a combination of the 6 components of FibroTest-ActiTest plus body mass index, serum cholesterol, triglycerides, and glucose adjusted for age and gender. SteatoTest area under the ROC curves was 0.79 (SE $=0.03)$ in the training group; $0.80(0.04)$ in validation group I; $0.86(0.03)$ in validation group 2; and $0.72(0.05)$ in the validation group 3 - all significantly higher than the standard markers: $\gamma$-glutamyl-transpeptidase or alanine aminotransferase. The median SteatoTest value was 0.13 in fasting controls; 0.16 in non-fasting controls; 0.31 in patients without steatosis; 0.39 in grade I steatosis $(0-5 \%) ; 0.58$ in grade $2(6-32 \%)$; and 0.74 in grade $3-4(33-100 \%)$. For the diagnosis of grade $2-4$ steatosis, the sensitivity of SteatoTest at the 0.30 cut-off was $0.91,0.98,1.00$ and 0.85 and the specificity at the 0.70 cut-off was $0.89,0.83,0.92,1.00$, for the training and three validation groups, respectively.

Conclusion: SteatoTest is a simple and non-invasive quantitative estimate of liver steatosis and may reduce the need for liver biopsy, particularly in patients with metabolic risk factor. 


\section{Background}

Fatty liver or hepatic steatosis is defined as an excessive accumulation of fat in hepatocytes [1]. On worldwide grounds, the prevalence of steatosis is very high, and is associated with several factors such as alcohol, diabetes, overweight, hyperlipidemia, insulin resistance, hepatitis C genotype 3, abetalipoproteinemia and administration of some drugs [1-4].

Fatty liver disease involves the accumulation of triglycerides in hepatocytes, apoptosis, hepatocellular ballooning, Mallory's hyaline, necrosis of hepatocytes, lobular inflammation [5,6], small hepatic vein obliteration [7] and often fibrosis with possible progression to cirrhosis, hepatocellular cancer and liver-related death $[1,4,8,9]$.

Non-alcoholic fatty liver disease (NAFLD) is an adaptive response of the liver to insulin resistance. The natural progression of insulin resistance and endogenous noxious insults (such as free radical production, mitochondrial dysfunction, endotoxin) which are, at least in part, related to the presence of excessive fat in the liver, can trigger the development of non-alcoholic steatohepatitis (NASH). $\mathrm{NASH}$ itself can induce a fibrogenic response that can result in cirrhosis $[5,6]$.

In patients with alcoholic liver disease (ALD) [10,11], chronic hepatitis $C[12]$, and possibly in those with hepatitis B [13], the presence of steatosis is also associated with fibrosis progression, with or without associated necroinflammatory lesions (alcoholic or viral hepatitis).

Current guidelines recommend liver biopsy as part of the management of chronic liver disease [14]. This procedure provides important information regarding the degree of liver damage, in particular the severity of necroinflammatory activity, fibrosis and steatosis [14]. Unfortunately, liver biopsy has a potential sampling error, is invasive, costly and prone to complications as well [15-19]. Up to $30 \%$ of patients experience pain following the procedure; $0.3 \%$ have severe complications; and mortality approaches $0.01 \%[20,21]$.

As a result of those limitations as well as patient reluctance to undergo liver biopsy, the estimate of liver injury using non-invasive biomarkers has gained a growing importance [20-22]. For the diagnosis of fibrosis, FibroTest (FT) (Biopredictive, Paris France) has been validated as a surrogate marker in chronic hepatitis C [23] and B [24] and, recently, in ALD $[25,26]$. A preliminary study has also observed a similar diagnostic value in NAFLD [27]. ActiTest (AT) (Biopredictive, Paris France) has been validated as a surrogate marker for necrosis in chronic hepatitis C [23] and B [24]. Nonetheless, and despite those tests, biopsy was still useful for the diagnosis of steatosis and steatohepatitis.

For the diagnosis of steatosis, there is no standard recommendation. The usual recommendation is to measure $\gamma$ glutamyl-transpeptidase (GGT) and alanine aminotransferase (ALT) and, in addition, to perform liver biopsy for grading and staging $[1,3,4,14]$. The evaluation of liver steatosis using ultrasonography is subjective as based on echo intensity (echogenicity) and special patterns of echoes (texture) and is inaccurate in patients with advanced fibrosis [28]. Up to now, no study has demonstrated that a single or a panel of biomarkers can be used as an alternative to liver biopsy for the diagnosis of steatosis, whether induced by alcohol, viral hepatitis or NAFLD, the most common causes of steatosis.

The objective of the current study was to create a new panel of biomarkers known as SteatoTest (ST) with sufficient predictive values for the diagnosis of steatosis due to alcohol, NAFLD and hepatitis C and B. Serum GGT and ALT were considered as the standard biochemical markers [3].

\section{Results \\ Patients}

A total of 2,272 subjects were analyzed (Figure 1), being 884 subjects included in the biomarker validation study, distributed as follows: 310 patients in the training group; 171 in the validation group $1 ; 201$ in the validation group 2; 62 in the validation group 3; and 140 subjects in the control group. The 1,388 non-included patients were not significantly different from the 884 patients integrated in the validation assay (data not shown).

\section{Comparison between groups (Table I)}

Patients included in the 4 groups were similar in age with a predominance of male subjects (range 61-76\%). The prevalence of steatosis greater than $5 \%$ (grades 2 to 4 ) varied from $11 \%$ in hepatitis $\mathrm{C}$ virus (HCV) cured patients to $94 \%$ in patients with ALD. In all groups, at least one metabolic risk factor was observed in more than $50 \%$ of included patients. Patients in group 3 with alcoholic liver disease were more often male, older, had smaller liver biopsies, more metabolic risk factors, more extensive fibrosis and more grades 2-4 steatosis than the three other groups. Validation group 2 with HCV cured patients had quasi-normal characteristics with normal liver tests and only $11 \%$ grade $2-4$ steatosis.

\section{Factors associated with steatosis (Table 2)}

In the training group the most significant components associated with the presence of grade 2-4 steatosis in univariate analysis were body mass index (BMI), age, ALT, aspartate aminotransferase (AST), GGT, glucose, and trig- 


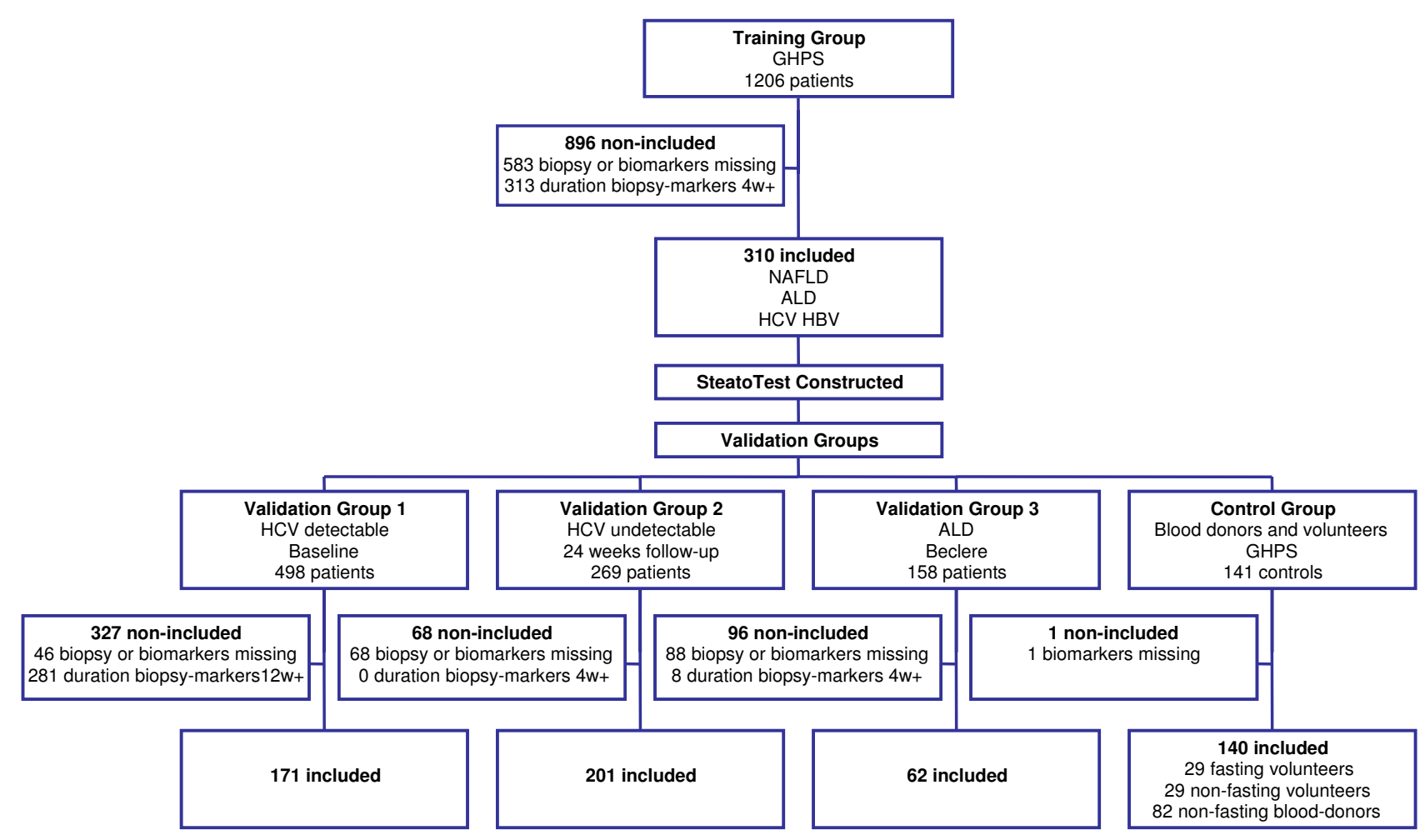

Figure I

Flow chart of patients analyzed and included in the training and validation groups.

lycerides. The logistic regression defining the ST included 12 components - ALT, $\alpha_{2}$-macroglobulin (A2M), apolipoprotein A-I (ApoA1), haptoglobin, total bilirubin, GGT, cholesterol, triglycerides, glucose, age, gender and BMI. In logistic regression analyses, the most significant components were BMI $(P=0.0002)$, GGT $(P=0.002)$, ApoA1 ( $P$ $=0.01), \mathrm{A} 2 \mathrm{M}(\mathrm{P}=0.02), \mathrm{ALT}(\mathrm{P}=0.03)$ and triglycerides $(P=0.04)$. In the validation group, similar differences were observed, most significantly for BMI, GGT, ALT and triglycerides (Table 2).

\section{Distribution of SteatoTest according to steatosis grades (Figure 2)}

The median ST value was 0.13 in fasting controls; 0.18 in non-fasting controls; 0.14 in blood donors; 0.26 in patients without steatosis; 0.43 in grade 1 steatosis; 0.62 in grade 2; 0.70 in grade 3 ; and 0.75 in grade 4 . Because there were not a sufficient number of patients with grade 3 and 4, these two groups were combined (Figure 2).

\section{Diagnostic value of SteatoTest (Tables 3 and 4)}

The values $\{$ Area under the ROC curves (AUROCs) $\}$ of ST, GGT and ALT for the diagnosis of grades 2-4 steatosis, in the training and validation groups, are given in Table 3. ST had higher AUROCs: $\{0.79(\mathrm{SE}=0.03)\}$ in training group; $0.80(0.04)$ in validation group $1 ; 0.86(0.03)$ in validation group 2; and $0.72(0.05)$ in validation group 3 . These were always significantly higher than the AUROCs of GGT and significantly higher than the AUROCs of ALT, for the training group and validation group 1 (Table 3). The distribution of ST, GGT and ALT, according to the severity of steatosis, is illustrated in Figure 2 for the training and validation groups.

The diagnostic values of ST, GGT and ALT according to cutoffs are shown in Table 4. For the diagnosis of grade 24 steatosis, the sensitivity of ST at the 0.30 cut-off was $0.91,0.98,1.00$ and 0.85 and the specificity at the 0.70 cut-off was $0.89,0.83,0.92$, and 1.00 , for the training and validation groups, respectively.

In the training group, there were 56 cases (18\%) of significant discordance between steatosis percentage as predicted by ST and that observed in biopsy samples. Failure attributable to ST (false positive of ST) was suspected in one case that had acute drug hepatitis associated with chronic hepatitis B. Failure attributable to biopsy (false negatives of biopsy) was suspected in 16 cases with poor quality biopsy samples (median length $13 \mathrm{~mm}, 2$ fragments) and, at least, one metabolic risk factor. For the val- 
Table I: Characteristics of the patients.

\begin{tabular}{|c|c|c|c|c|}
\hline Characteristics & $\begin{array}{l}\text { Training } \\
\text { group }\end{array}$ & $\begin{array}{l}\text { Validation Group I - } \\
\text { HCV before treatment }\end{array}$ & $\begin{array}{l}\text { Validation Group } 2 \text { - } \\
\text { HCV sustained } \\
\text { responders }\end{array}$ & $\begin{array}{c}\text { Validation Group } 3 \text { - } \\
\text { Alcoholic liver } \\
\text { disease }\end{array}$ \\
\hline Number of patients & 310 & $17 \mid$ & 201 & 62 \\
\hline Age at biopsy, years & $48.9(12.4)$ & $44.1(7.2)$ & $43.6(8.0)$ & $46.6(9.8)$ \\
\hline Male & $20 \mathrm{I}(65 \%)$ & III (65\%) & $122(6 \mid \%)$ & $47 / 62(76 \%)$ \\
\hline Female & $109(35 \%)$ & $60(35 \%)$ & 79 (39\%) & $15(24 \%)$ \\
\hline $\mathrm{BMI}, \mathrm{kg} / \mathrm{m}^{2}$ & $25.4(5.1)$ & $27.7(5.0)$ & $26.5(4.8)$ & $24.2(4.1)$ \\
\hline \multicolumn{5}{|l|}{ Biopsy quality } \\
\hline Length & $17.0(6.2)$ & $16.6(15.5)$ & $17.0(8.2)$ & $13.5(6.8)$ \\
\hline Length $\geq 15 \mathrm{~mm}$ & $205(67 \%)$ & $82(48 \%)$ & $96(48 \%)$ & $15(24 \%)$ \\
\hline Number of fragments & $2.5(2.3)$ & - & - & $1.9(1.6)$ \\
\hline One fragment & $128 / 278(46 \%)$ & - & - & $37(60 \%)$ \\
\hline Duration biopsy-serum, mean (days range) & $\mathrm{I}(0-30)$ & $40(0-90)$ & II (0-45) & $7(0-14)$ \\
\hline \multicolumn{5}{|l|}{ Liver Risk factor } \\
\hline $\mathrm{HCV}$ & $211(68 \%)$ & $17 \mid(100 \%)$ & $0(0 \%)$ & $0(0 \%)$ \\
\hline HBV & $18(6 \%)$ & $0(0 \%)$ & $0(0 \%)$ & $0(0 \%)$ \\
\hline NAFLD & $69(22 \%)$ & $0(0 \%)$ & $0(0 \%)$ & $0(0 \%)$ \\
\hline ALD & $12(4 \%)$ & $0(0 \%)$ & $0(0 \%)$ & $0(0 \%)$ \\
\hline Daily alcohol $=50 \mathrm{~g} /$ day & $34 / 236(14 \%)$ & $0(0 \%)$ & $0(0 \%)$ & $62(100 \%)$ \\
\hline Cured HCV infection & $0(0 \%)$ & $0(0 \%)$ & $201(100 \%)$ & $0(0 \%)$ \\
\hline \multicolumn{5}{|l|}{ Metabolic factor } \\
\hline $\mathrm{BMI} \geq 27.0$ & $92(30 \%)$ & $88(51 \%)$ & $77(38 \%)$ & $14(23 \%)$ \\
\hline Glucose $\geq 6.0 \mathrm{mmol} / \mathrm{L}$ & $63(20 \%)$ & $30(18 \%)$ & 27 (13\%) & $20(32 \%)$ \\
\hline Triglycerides $\geq 1.7 \mathrm{mmol} / \mathrm{L}$ & $67(22 \%)$ & $36(21 \%)$ & $54(27 \%)$ & $20(32 \%)$ \\
\hline Cholesterol $\geq 6.0 \mathrm{mmol} / \mathrm{L}$ & 61 (20\%) & $12(7 \%)$ & $26(13 \%)$ & $23(37 \%)$ \\
\hline \multicolumn{5}{|l|}{ Metabolic factor: number per patient } \\
\hline None & $132(43 \%)$ & $60(35 \%)$ & $96(48 \%)$ & $17(27 \%)$ \\
\hline One & 101 (33\%) & $64(37 \%)$ & $72(36 \%)$ & $20(32 \%)$ \\
\hline Two & $52(17 \%)$ & $39(23 \%)$ & $31(15 \%)$ & $19(31 \%)$ \\
\hline Three & $22(7 \%)$ & $8(5 \%)$ & $0(0 \%)$ & $5(8 \%)$ \\
\hline Four & $3(1 \%)$ & $0(0 \%)$ & $2(1 \%)$ & I (2\%) \\
\hline \multicolumn{5}{|l|}{ Liver steatosis grade } \\
\hline None $(0 \%)$ & $130(42 \%)$ & $58(34 \%)$ & $116(58 \%)$ & $2(3 \%)$ \\
\hline Mild (Score I-5\%) & $40(13 \%)$ & $68(40 \%)$ & $63(31 \%)$ & $2(3 \%)$ \\
\hline Moderate (Score 6-33\%) & $69(22 \%)$ & $35(20 \%)$ & $17(8 \%)$ & $42(68 \%)$ \\
\hline Marked (Score 34-66\%) & $36(12 \%)$ & $7(4 \%)$ & $4(3 \%)$ & $12(19 \%)$ \\
\hline Severe (Score 67-100\%) & 35 (1 I\%) & $3(2 \%)$ & $\mathrm{I}(0.5 \%)$ & $4(7 \%)$ \\
\hline \multicolumn{5}{|l|}{ Liver fibrosis stage at biopsy } \\
\hline F0 - No fibrosis & $62(20 \%)$ & $0(0 \%)$ & $16(8 \%)$ & $8(13 \%)$ \\
\hline FI - Fibrosis without septa & 127 (4I\%) & $102(60 \%)$ & $136(68 \%)$ & $23(37 \%)$ \\
\hline F2 - Few septa & $52(17 \%)$ & $39(23 \%)$ & $33(16 \%)$ & $11(18 \%)$ \\
\hline F3 - Many septa & $36(11 \%)$ & $19(11 \%)$ & $9(4 \%)$ & $7(11 \%)$ \\
\hline F4 - Cirrhosis & $33(11 \%)$ & $11(6 \%)$ & $7(3 \%)$ & $13(21 \%)$ \\
\hline \multicolumn{5}{|l|}{ Markers (normal range) } \\
\hline AST, IU/L (I7-27 female; 20-32 male) & $83(159)$ & $82(57)$ & $23(9)$ & $89(83)$ \\
\hline ALT, IU/L (I I-26 female; I6-35 male) & $109(114)$ & $118(94)$ & $19(10)$ & $72(88)$ \\
\hline Total bilirubin, $\mathrm{mol} / \mathrm{L}(\mathrm{I}-2 \mathrm{I})$ & $14.8(26.2)$ & II.I (4.8) & $8.8(4.6)$ & $21.5(19.6)$ \\
\hline GGT, U/L (7-32 female; II-49 male) & $112(183)$ & $84(96)$ & $21(18)$ & $323(443)$ \\
\hline A2M, g/L (female I·6-4.0; male I·4-3·3) & $2.4(1.0)$ & $3.1(1.2)$ & $2.0(0.8)$ & $1.8(0.5)$ \\
\hline ApoAl g/L $(|\cdot 2-| \cdot 7)$ & $1.4(0.3)$ & $1.3(0.3)$ & $1.2(0.3)$ & $1.5(0.5)$ \\
\hline Haptoglobin, g/L $(0 \cdot 35-2 \cdot 00)^{*}$ & $0.95(0.57)$ & $0.78(0.45)$ & $0.86(0.43)$ & $1.39(0.63)$ \\
\hline Glucose, $\mathrm{mmol} / \mathrm{L}$ & $5.5(3.2)$ & $5.4(1.2)$ & $5.3(1.0)$ & $5.8(1.6)$ \\
\hline Cholesterol, $\mathrm{mmol} / \mathrm{L}$ & $4.9(1.3)$ & $4.5(1.0)$ & $5.0(1.0)$ & $5.4(1.9)$ \\
\hline Triglycerides, $\mathrm{mmol} / \mathrm{L}$ & $\mathrm{I} .5(\mathrm{I} .4)$ & $\mathrm{I} .4(0.8)$ & $1.6(1.0)$ & $1.9(3.1)$ \\
\hline FibroTest & $0.42(0.28)$ & $0.47(0.26)$ & $0.29(0.20)$ & $0.43(0.28)$ \\
\hline SteatoTest & $0.49(0.25)$ & $0.53(0.22)$ & $0.36(0.22)$ & $0.58(0.25)$ \\
\hline
\end{tabular}

Data are mean (SD) or proportion. BMI = body mass index; $\mathrm{HCV}=$ hepatitis $\mathrm{C}$ virus; $\mathrm{HBV}=$ hepatitis $B$ virus; NAFLD = non-alcoholic fatty liver disease; ALD = alcoholic liver disease; AST = aspartate aminotransferase; ALT = alanine aminotransferase; GGT = $\gamma$-glutamyl transpeptidase; $\mathrm{A} 2 \mathrm{M}=$ $\alpha_{2}$-macroglobulin; ApoAI = apolipoprotein AI. 
Table 2: Characteristics of the patients, according to the presence of steatosis.

\begin{tabular}{|c|c|c|c|c|c|c|}
\hline \multirow[t]{2}{*}{ Characteristic } & \multicolumn{3}{|c|}{ Steatosis Training Group } & \multicolumn{3}{|c|}{$\begin{array}{c}\text { Steatosis Validation Group I - HCV before } \\
\text { treatment }\end{array}$} \\
\hline & $<5 \%, n=170$ & $\geq \mathbf{5} \%, n=140$ & $P$ value & No, $n=126$ & Yes, $n=45$ & $P$ value \\
\hline \multicolumn{7}{|l|}{ Demographics } \\
\hline Age at biopsy, years & $46.7(12.4)$ & $51.8(12.1)$ & 0.0004 & $43.7(7.3)$ & $45.2(7.0)$ & 0.28 \\
\hline Male gender & $110(55 \%)$ & $91(45 \%)$ & 0.96 & $81(64 \%)$ & $30(67 \%)$ & 0.77 \\
\hline BMI & $24(4)$ & $27(6)$ & $<0.0001$ & $27(5)$ & $31(4)$ & $<0.0001$ \\
\hline \multicolumn{7}{|l|}{ Biochemical markers } \\
\hline$\alpha_{2}$-macroglobulin, g/L & $2.47(1.00)$ & $2.30(1.04)$ & 0.07 & $3.10(1.23)$ & $3.20(1.24)$ & 0.50 \\
\hline ALT, IU/L & $104(119)$ & $115(108)$ & 0.02 & $46(45)$ & $61(48)$ & 0.003 \\
\hline AST, IU/L & $83(204)$ & $83(78)$ & 0.01 & $80(61)$ & $88(43)$ & 0.01 \\
\hline Apolipoprotein AI, g/L & $1.46(0.34)$ & $1.42(0.33)$ & 0.30 & $1.27(0.26)$ & $1.20(0.24)$ & 0.18 \\
\hline Haptoglobin, g/L & $0.93(0.60)$ & $0.96(0.52)$ & 0.19 & $0.77(0.45)$ & $0.78(0.44)$ & 0.84 \\
\hline GGT, IU/L & $83(132)$ & $147(226)$ & $<0.0001$ & $72(85)$ & $118(116)$ & 0.0007 \\
\hline Total bilirubin, $\mu \mathrm{mol} / \mathrm{L}$ & $14.8(3 \mid .4)$ & $14.7(17.8)$ & 0.47 & $\mid I .0(5.0)$ & $11.3(4.1)$ & 0.38 \\
\hline Glucose $\mathrm{mmol} / \mathrm{L}$ & $5.1(3.7)$ & $5.9(2.2)$ & $<0.0001$ & $5.2(0.9)$ & $6.0(1.8)$ & 0.0007 \\
\hline Triglycerides, $\mathrm{mmol} / \mathrm{L}$ & $1.24(0.95)$ & $1.88(1.78)$ & $<0.0001$ & $1.26(0.72)$ & $1.72(1.0)$ & 0.0008 \\
\hline Total cholesterol, $\mathrm{mmol} / \mathrm{L}$ & $4.8(1.2)$ & $5.1(1.4)$ & 0.10 & $4.5(1.0)$ & $4.4(1.0)$ & 0.10 \\
\hline FibroTest & $0.40(0.29)$ & $0.45(0.28)$ & 0.47 & $0.45(0.26)$ & $0.53(0.24)$ & 0.07 \\
\hline SteatoTest & $0.38(0.21)$ & $0.62(0.22)$ & $<0.0001$ & $0.47(0.21)$ & $0.70(0.16)$ & $<0.0001$ \\
\hline \multirow[t]{2}{*}{ Characteristic } & \multicolumn{3}{|c|}{$\begin{array}{c}\text { Steatosis Validation Group } 2-\mathrm{HCV} \text { sustained } \\
\text { responders }\end{array}$} & \multicolumn{3}{|c|}{$\begin{array}{c}\text { Steatosis Validation Group } 3 \text { - Alcoholic liver } \\
\text { disease }\end{array}$} \\
\hline & No $n=179$ & Yes $n=22$ & $P$ value & $<5 \%, n=4$ & $\geq 5 \%, n=58$ & $P$ value \\
\hline \multicolumn{7}{|l|}{ Demographics } \\
\hline Age at biopsy, years & $43.7(8.1)$ & $43.1(7.0)$ & 0.7 & $38.0(12.8)$ & $47(9.4)$ & 0.16 \\
\hline Male gender & $110(62 \%)$ & $12(55 \%)$ & 0.53 & $2(50 \%)$ & 45 (78\%) & 0.21 \\
\hline BMI & $26(4)$ & $31(6)$ & $<0.0001$ & $22.9(2.9)$ & $24.3(4.2)$ & 0.49 \\
\hline \multicolumn{7}{|l|}{ Biochemical markers } \\
\hline$\alpha_{2}$-macroglobulin, g/L & $2.08(0.79)$ & $1.73(0.66)$ & 0.06 & $2.12(0.53)$ & I.8I (0.55) & 0.26 \\
\hline$A L T, I U / L$ & $18(9)$ & $26(9)$ & $<0.0001$ & $35(24)$ & $74(90)$ & 0.10 \\
\hline AST, IU/L & $23(9)$ & $25(7)$ & 0.06 & $74(43)$ & $58(90)$ & 1.00 \\
\hline Apolipoprotein AI, g/L & $1.16(0.28)$ & $1.07(0.25)$ & 0.2 & $1.67(0.43)$ & $\mathrm{I} .48(0.49)$ & 0.49 \\
\hline Haptoglobin, g/L & $0.85(0.4 \mathrm{I})$ & $0.94(0.56)$ & 0.85 & $1.55(0.92)$ & $1.38(0.62)$ & 0.85 \\
\hline GGT, IU/L & $20(18)$ & $28(14)$ & 0.0002 & $327(184)$ & $323(323)$ & 0.41 \\
\hline Total bilirubin, $\mu \mathrm{mol} / \mathrm{L}$ & $8.9(4.6)$ & $8.1(4.3)$ & 0.3 & $28.5(23.4)$ & $21.1(19.5)$ & 0.28 \\
\hline Glucose, $\mathrm{mmol} / \mathrm{L}$ & $5.3(1.0)$ & $5.5(0.8)$ & 0.16 & $6.5(2.2)$ & $5.7(1.6)$ & 0.46 \\
\hline Triglycerides, mmol/L & $1.49(0.98)$ & $2.05(1.22)$ & 0.003 & $\mathrm{I} .05(0.5 \mathrm{I})$ & $1.96(3.15)$ & 0.28 \\
\hline Total cholesterol, $\mathrm{mmol} / \mathrm{L}$ & $5.0(1.0)$ & $5.1(0.9)$ & 0.51 & $6.0(1.38)$ & $5.4(2.0)$ & 0.68 \\
\hline FibroTest & $0.29(0.20)$ & $0.26(0.19)$ & 0.46 & $0.43(0.32)$ & $0.43(0.28)$ & 0.79 \\
\hline SteatoTest & $0.32(0.20)$ & $0.62(0.17)$ & $<0.0001$ & $0.44(0.03)$ & $0.59(0.26)$ & 0.21 \\
\hline
\end{tabular}

Data are mean (SD) or proportion.

idation' groups, significant discordance was observed in 17 cases $(16 \%)$ in group $1 ; 20$ cases $(10 \%)$ in group 2 ; and 13 cases $(21 \%)$ in group 3 . Significant discordance was observed more often in patients with extensive fibrosis (stage F3 or F4): 38 cases out of 135 (28\%) versus 91 cases out of $609(15 \%)-\mathrm{P}=0.001$.

\section{Repeated biopsies and repeated SteatoTest}

A total of 75 patients were included with biopsy at baseline and at follow-up. Among them, 23 had an improvement of steatosis (one of 3 grades, two of 2 grades and twenty of one grade); 43 had no change in steatosis grade; and 9 had worsening of one grade. ST significantly decreased in 23 patients with steatosis improvement at biopsy from $0.60(\mathrm{SE}=0.05)$ to $0.41(0.05)$, a significantly greater difference $(\mathrm{P}=0.001)$ than that observed in 52 patients without biopsy improvement: from 0.44 (0.03) to $0.31(0.03)$.

\section{Integrated database}

A total of 884 subjects were included in the integrated database combining the training group, the three valida- 
A: Training Group
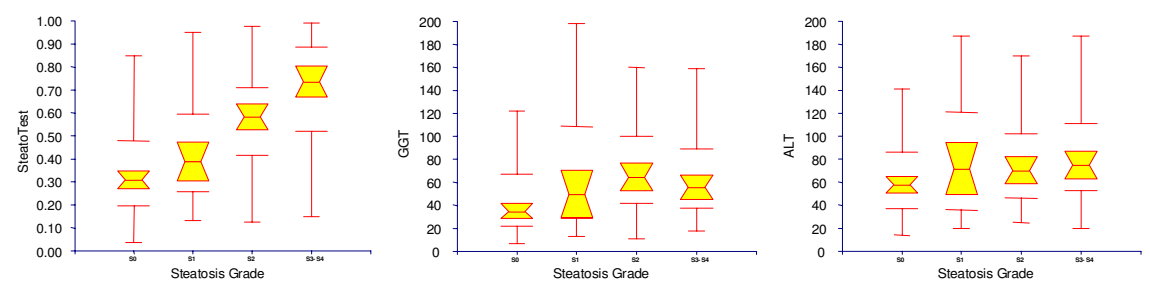

B: Validation Group 1
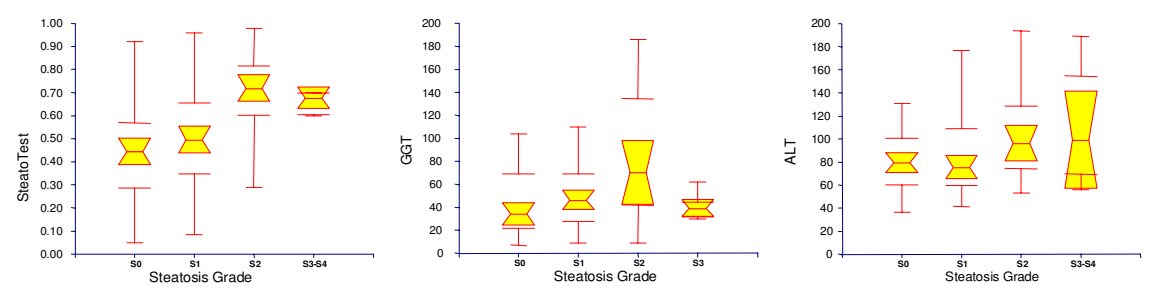

C: Validation Group 2
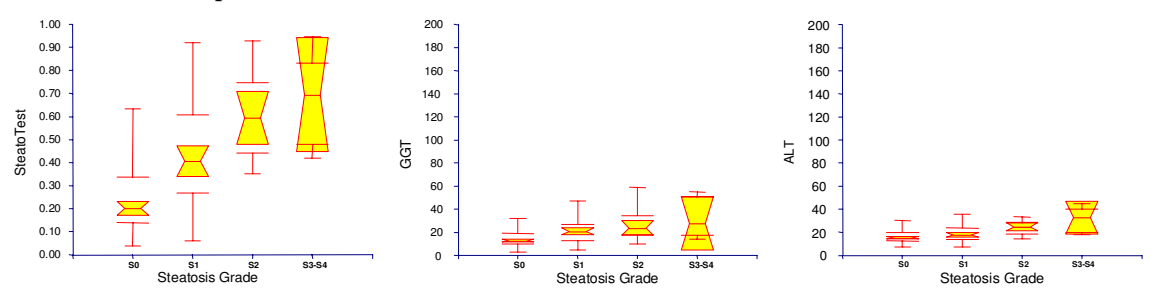

D: Validation Group 3
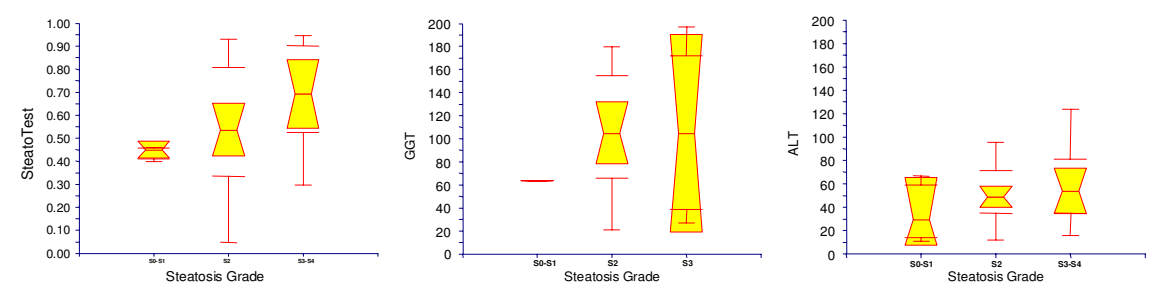

E: SteatoTest in Control Groups

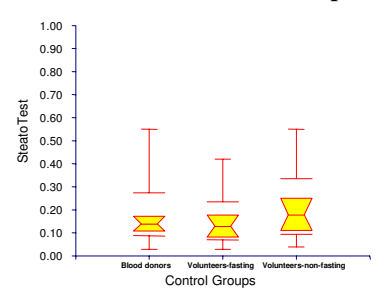

\section{Figure 2}

Relationship between ST, GGT and ALT and the grade of liver steatosis. A four grades scoring system was used to assess steatosis: SO - no steatosis; SI - mild, I to 5\%; S2 - moderate, 6 to 32\%; S3-S4 - marked or severe, 33 to 100\%.

Notched box plots showing the relationship (A) in the training group; (B) in validation group I, HCV patients before treatment; (C) group 2, HCV sustained responders; (D) group 3, alcoholic liver disease; and $(E)$ in controls, healthy volunteers fasting and non-fasting and non-fasting blood donors. The horizontal line inside each box represents the median and the width of each box the median \pm 1.57 interquartile range/vn for assessing the $95 \%$ level of significance between group medians. Failure of the shaded boxes to overlap corresponds to statistical significance $(P<0.05)$. The horizontal lines above and below each box encompass the interquartile range (from $25^{\text {th }}$ to $75^{\text {th }}$ percentile), and the vertical lines from the ends of the box encompass the adjacent values (upper: $75^{\text {th }}$ percentile plus 1.5 times interquartile range, lower $25^{\text {th }}$ percentile minus 1.5 times interquartile range). In validation group 3, almost all patients had steatosis and group SO and SI were combined. 
Table 3: Values AArea under the ROC curves (AUROCs)\} of SteatoTest, GGT and ALT for the diagnosis of steatosis greater than $5 \%$, in both training and validation groups.

\begin{tabular}{cccccc}
\hline Diagnostic panel & $\begin{array}{c}\text { Training Group } \\
\text { AUROC (se) }\end{array}$ & $\begin{array}{c}\text { Validation Group I } \\
- \text { HCV before } \\
\text { treatment }\end{array}$ & $\begin{array}{c}\text { Validation Group 2 } \\
- \text { HCV sustained } \\
\text { responders }\end{array}$ & $\begin{array}{c}\text { Validation Group 3 } \\
\text { - Alcoholic liver } \\
\text { disease }\end{array}$ & All groups \\
& $\mathrm{N}=310$ & $\mathrm{~N}=171$ & $\mathrm{~N}=201$ & $\mathrm{~N}=62$ & $\mathrm{~N}=884$ \\
SteatoTest & $0.79(0.03)^{*}$ & $0.80(0.04) \in$ & $0.86(0.03) \$$ & $0.72(0.05) * *$ & $0.80(0.02) \in t$ \\
GGT & $0.66(0.03)$ & $0.67(0.05)$ & $0.74(0.05)$ & $0.50(0.09)$ & $0.66(0.02)$ \\
ALT & $0.58(0.03)$ & $0.62(0.05)$ & $0.79(0.04)$ & $0.66(0.07)$ & $0.61(0.02)$ \\
\hline
\end{tabular}

* - Higher than GGT $(P<0.000 \mathrm{I})$ and ALT $(\mathrm{P}<0.000 \mathrm{I}) ; \varepsilon$ - Higher than GGT $(\mathrm{P}=0.007)$ and ALT $(\mathrm{P}<0.000 \mathrm{I})$; $\$-$ Higher than GGT $(\mathrm{P}=0.02)$;

** - Higher than GGT $(P=0.002) ; £ £$ Higher than GGT $(P<0.000 I)$ and ALT $(P<0.000 I)$.

tion groups and the control group. Of these, 75 patients with HCV were investigated twice (once before and then after treatment), and 29 volunteers were investigated twice (while fasting and, then, non-fasting). There was a very significant overall correlation between ST and the steatosis grades from controls to S3 (Figure 3). For ST, there was a significant difference between all histological grades by Tukey-Kramer multiple comparison test for all pairwise differences between means $(P<0.05)$. For GGT and ALT, there was no significant difference between S0 and S1. For ALT, there was no significant difference between S0 and S2, S1 and S2, and S2 and S3, either. ST has higher AUROC, $0.80(0.02)$ than all the isolated components for the diagnosis of steatosis grade 2-4: ALT, GGT

Table 4: Diagnostic value of SteatoTest for predicting liver steatosis greater than $5 \%$.

\begin{tabular}{|c|c|c|c|c|}
\hline Cut-off & Sensitivity & Specificity & $\begin{array}{c}\text { Positive Predictive } \\
\text { Value }\end{array}$ & $\begin{array}{c}\text { Negative Predictive } \\
\text { Value }\end{array}$ \\
\hline Training Group N $=310$ & & & Prevalence $=45 \%$ & \\
\hline SteatoTest 0.30 & $0.91(127 / 140)$ & $0.45(77 / 170)$ & $0.58(127 / 220)$ & $0.86(77 / 90)$ \\
\hline SteatoTest 0.50 & $0.69(97 / 140)$ & $0.74(126 / 170)$ & $0.69(97 / 141)$ & $0.75(126 / 169)$ \\
\hline SteatoTest 0.70 & $0.45(63 / 140)$ & $0.89(152 / 170)$ & $0.78(63 / 81)$ & $0.66(152 / 229)$ \\
\hline GGT 50 IU/L & $0.66(92 / 140)$ & $0.55(94 / 170)$ & $0.55(92 / 168)$ & $0.66(94 / 142)$ \\
\hline ALT $50 \mathrm{IU} / \mathrm{L}$ & $0.77(108 / 140)$ & $0.35(60 / 170)$ & $0.50(108 / 218)$ & $0.65(60 / 92)$ \\
\hline $\begin{array}{c}\text { Validation Group I } N= \\
\mid \text { I I }\end{array}$ & & & Prevalence $=26 \%$ & \\
\hline SteatoTest 0.30 & $0.98(44 / 45)$ & $0.24(30 / 126)$ & $0.31(44 / 140)$ & $0.97(30 / 3 \mathrm{I})$ \\
\hline SteatoTest 0.50 & $0.89(40 / 45)$ & $0.58(73 / 126)$ & $0.43(40 / 93)$ & $0.94(73 / 78)$ \\
\hline SteatoTest 0.70 & $0.44(20 / 45)$ & $0.83(105 / 126)$ & $0.49(20 / 4 \mathrm{I})$ & $0.81(105 / 130)$ \\
\hline GGT $50 \mathrm{IU} / \mathrm{L}$ & $0.62(28 / 45)$ & $0.61(72 / 126)$ & $0.34(28 / 82)$ & $0.81(72 / 89)$ \\
\hline ALT $50 \mathrm{IU} / \mathrm{L}$ & $1.00(45 / 45)$ & $0.06(8 / 126)$ & $0.28(45 / 163)$ & $1.00(8 / 8)$ \\
\hline $\begin{array}{c}\text { Validation Group } 2 \mathrm{~N}= \\
20 \mathrm{I}\end{array}$ & & & Prevalence $=11 \%$ & \\
\hline SteatoTest 0.30 & $1.00(22 / 22)$ & $0.56(100 / 179)$ & $0.22(22 / 101)$ & $1.00(100 / 100)$ \\
\hline SteatoTest 0.50 & $0.68(15 / 22)$ & $0.79(142 / 179)$ & $0.29(15 / 52)$ & $0.95(142 / 149)$ \\
\hline SteatoTest 0.70 & $0.32(7 / 22)$ & $0.92(165 / 179)$ & $0.33(7 / 21)$ & $0.92(165 / 180)$ \\
\hline GGT 50 IU/L & $0.09(2 / 22)$ & $0.97(174 / 179)$ & $0.29(2 / 7)$ & $0.90(174 / 194)$ \\
\hline ALT $50 \mathrm{IU} / \mathrm{L}$ & $0.05(1 / 22)$ & $0.98(176 / 179)$ & $0.25(1 / 3)$ & $0.89(176 / 197)$ \\
\hline $\begin{array}{c}\text { Validation Group } 3 \mathrm{~N}= \\
62\end{array}$ & & & Prevalence $=94 \%$ & \\
\hline SteatoTest 0.30 & $0.85(49 / 58)$ & $0.00(0 / 4)$ & $0.93(49 / 53)$ & $0.00(0 / 9)$ \\
\hline SteatoTest 0.50 & $0.62(36 / 58)$ & $1.00(4 / 4)$ & $1.00(36 / 36)$ & $0.15(4 / 26)$ \\
\hline SteatoTest 0.70 & $0.40(23 / 58)$ & $1.00(4 / 4)$ & $1.00(23 / 23)$ & $0.10(4 / 39)$ \\
\hline GGT 50 IU/L & $0.90(52 / 58)$ & $0.00(0 / 4)$ & $0.93(52 / 56)$ & $0.00(0 / 6)$ \\
\hline ALT $50 \mathrm{IU} / \mathrm{L}$ & $0.53(31 / 58)$ & $0.75(3 / 4)$ & $0.97(31 / 32)$ & $0.10(3 / 30)$ \\
\hline All Groups N = 884 & & & Prevalence $=30 \%$ & \\
\hline SteatoTest 0.30 & $0.90(238 / 265)$ & $0.54(336 / 619)$ & $0.46(238 / 52 I)$ & $0.93(336 / 363)$ \\
\hline SteatoTest 0.50 & $0.72(190 / 265)$ & $0.75(466 / 619)$ & $0.55(190 / 343)$ & $0.86(466 / 54 I)$ \\
\hline SteatoTest 0.70 & $0.46(122 / 265)$ & $0.88(546 / 619)$ & $0.63(122 / 195)$ & $0.79(546 / 689)$ \\
\hline GGT 50 IU/L & $0.66(174 / 265)$ & $0.76(468 / 619)$ & $0.54(174 / 325)$ & $0.84(468 / 559)$ \\
\hline ALT $50 \mathrm{IU} / \mathrm{L}$ & $0.72(185 / 265)$ & $0.62(382 / 619)$ & $0.44(185 / 422)$ & $0.83(382 / 462)$ \\
\hline
\end{tabular}



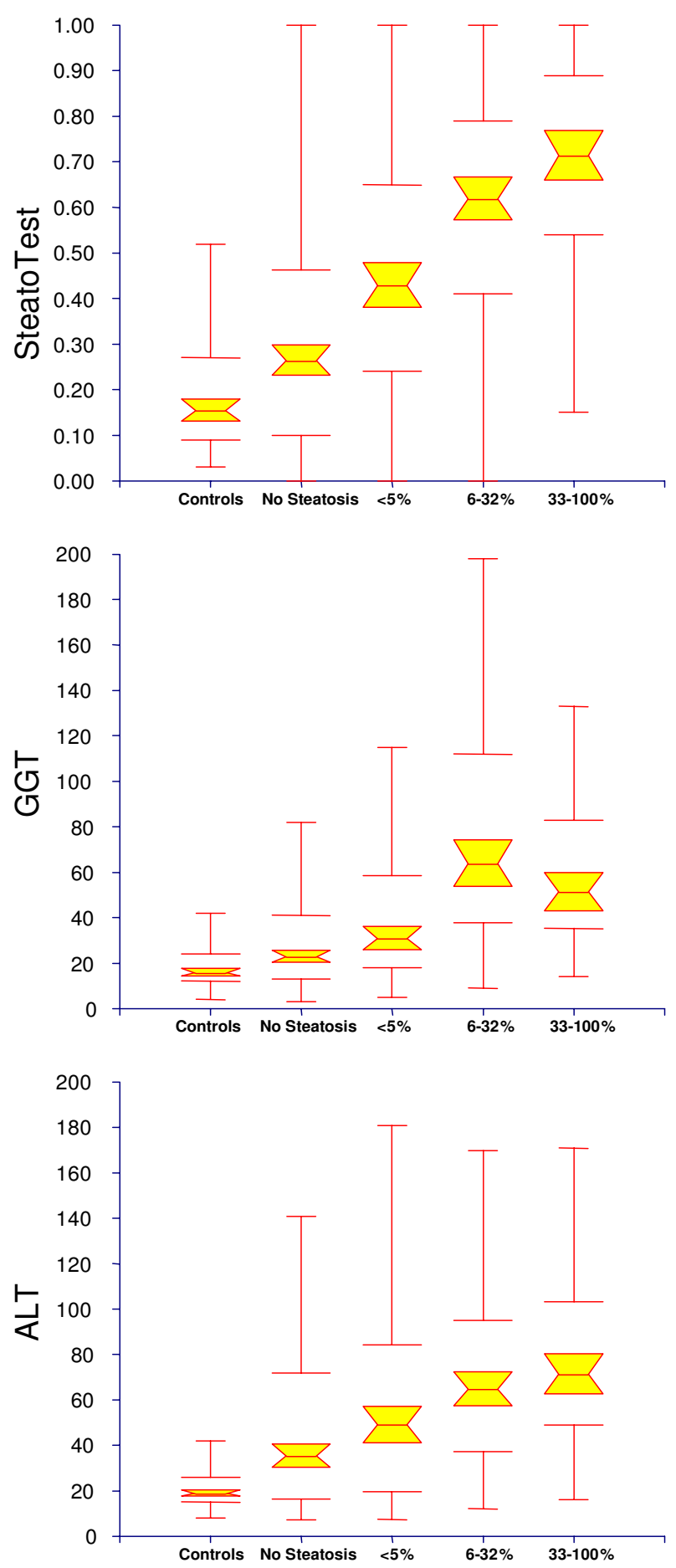

Figure 3

Relationship between ST, and the grade of liver steatosis in the integrated database combining controls, training group and validation groups. Failure of the shaded boxes to overlap indicates statistical significance between medians $(P<0.05)$. There was a significant difference between all grades by the Tukey-Kramer multiple comparison test for all pairwise differences between means $(P<0.05)$. For GGT and ALT, there was no significant difference between $S 0$ and $S I$ and between S2 and S3. For ALT, there was also no significant difference between S0 and S2, SI and S2. 
(Table 3), triglycerides 0.63 (0.02), BMI 0.61 (0.02), glucose $0.61(0.02)$, bilirubin $0.60(0.02)$, ApoA1 0.56 (0.02), A2M 0.56 (0.02) and cholesterol 0.53 (0.02) - all $P$ values $<0.03$.

A cut-off of 0.30 had $90 \%$ sensibility and a cut-off of 0.70 had $88 \%$ specificity permitting to achieve useful predictive values for steatosis grade 2-4, 93\% negative predictive value (NPV) and 63\% positive predictive value (PPV) for a steatosis prevalence of $30 \%$ (Table 4 ). The $90 \%$ specificity was obtained for a 0.72 cut-off with a corresponding $63 \%$ PPV. The overall percentage of patients classified with at least $90 \%$ sensitivity or $90 \%$ specificity was $59 \%$ $(363+156 / 884)$.

Among the 744 patients with biopsy, for the diagnosis of steatosis 3-4, the ST AUROC was 0.79 (0.02), significantly higher than GGT $0.74(0.02)(P=0.03)$, and ALT was $0.71(0.02)(P=0.007)$. The $90 \%$ sensitivity was obtained for a 0.32 cut-off; the $90 \%$ specificity was obtained for a 0.81 cut-off.

\section{Conversion between SteatoTest results and the corresponding steatosis grade}

ST is a continuous linear biochemical assessment of steatosis grade. It provides a numerical quantitative estimate of liver steatosis ranging from 0.00 to 1.00 , corresponding to a steatosis scoring system of grades S0 to S4. Among the 140 controls, the median ST value $( \pm$ SE) was $0.08 \pm 0.004$ (95th percentile, 0.23). Among the 744 patients with liver biopsy, the ST conversion was $0.000-0.3000$ for S0; $0.3001-0.3800$ for S0-S1; $0.3801-0.4800$ for S $1 ; 0.4801$ - 0.5700 for S1-S2; 0.5701 - 0.6700 for S2; 0.6701 0.6900 for S2-S3S4; and $0.6901-1.000$ for S3-S4.

\section{Steatosis at Ultrasonography and SteatoTest}

Ultrasonography has been preformed together with ST and biopsy in 304 patients. Concordance between steatosis diagnosed, at ultrasonography and at biopsy, was lower (kappa coefficient $=0.32 \pm 0.05$ ) than the concordance with ST (at 0.50 cut-off, kappa $=0.44 \pm 0.06 ; \mathrm{P}=$ 0.02 ), as well as lower AUROC $0.65 \pm 0.03$ for ultrasonography versus $0.78 \pm 0.03$ for ST $(\mathrm{P}=0.001)$. The ST values according to the presence of histological and radiological steatosis are given in Table 5.

\section{Sensitivity analyses}

A total of 635 (85\%) patients had a time lapse between biopsy and serum smaller than one month. The AUROC of ST was similar in those patients $(0.77,95 \%$ CI $0.73-$ $0.80)$ than in the $109(15 \%)$ patients with greater lapse $(0.82,95 \%$ CI $0.72-0.89 ; \mathrm{P}=0.36)$. A total of $670(78 \%)$ patients had a biopsy sample length smaller than $20 \mathrm{~mm}$. The AUROC of ST was slightly smaller in those patients $(0.76,95 \%$ CI $0.71-0.79)$ than in the 161 (15\%) patients with greater sample $(0.82,95 \%$ CI $0.74-0.88 ; \mathrm{P}=0.10)$.

\section{Discussion}

Our results highlight the utility of a new panel of biochemical markers (ST) for the prediction of steatosis of different origins. A cut-off of 0.30 had $90 \%$ sensibility and a cut-off of 0.72 had $90 \%$ specificity permitting to achieve useful predictive value, 93\% NPV and 63\% PPV for a steatosis prevalence of $30 \%$. These predictive values are far from perfection, particularly for PPV; however, already predictive and significantly higher than those of previous usual markers GGT, ALT and ultrasonography, as demonstrated by the increase of AUROCs. This benefit was observed for the most frequent chronic liver diseases: chronic viral hepatitis, and alcoholic and non-alcoholic fatty liver diseases.

We have not identified any reports of a single or a combination of biomarkers with accurate value for the diagnosis of steatosis in different chronic liver diseases. Marceau et al observed in 551 severely obese patients with liver biopsy that steatosis was associated with male gender, age, BMI, waist/hip ratio, diabetes, systolic blood pressure, fasting blood sugar, triglycerides, and non-HDL cholesterol, but no diagnostic algorithm was provided [29]. Papadia et al. [30] observed in 1000 obese patients an association between steatosis and AST, ALT, AST/ALT ratio, body weight, waist/hip ratio, serum glucose, serum triglycerides, BMI, GGT, age, and unconjugated bilirubin using regression analysis [30]. No panel was constructed and they concluded that no reliable biochemical marker could identify patients with severe steatosis with sufficient sensitivity for avoiding liver biopsy. Loguercio et al. [31] observed that in 305 patients with abnormal GGT or ALT, age, ferritin and tissue 4-hydroxynonenal were associated with steatosis. On multivariate analysis, no single factor was found to be an independent predictor [31].

Table 5: SteatoTest value according to presence of liver steatosis greater than $\mathbf{5 \%}$ at liver biopsy, and according to presence at ultrasonography.

\begin{tabular}{cccc}
\hline & No steatosis at biopsy & Steatosis at biopsy & Significance \\
\hline $\begin{array}{c}\text { No steatosis at } \\
\text { ultrasonography }\end{array}$ & $\mathrm{N}=143, \mathrm{ST}=0.37 \pm 0.02$ & $\mathrm{~N}=74, \mathrm{ST}=0.55 \pm 0.02$ & $<0.000 \mathrm{I}$ \\
$\begin{array}{c}\text { Steatosis at ultrasonography } \\
\text { Significance }\end{array}$ & $\mathrm{N}=25, \mathrm{ST}=0.47 \pm 0.04$ & $\mathrm{~N}=62, \mathrm{ST}=0.70 \pm 0.03$ & $<0.000 \mathrm{I}$ \\
& $0.0 \mathrm{I}$ & $\begin{array}{c}<0.000 \mathrm{I} \\
\end{array}$ &
\end{tabular}


In the present study, the predictive value of ST was related to the discriminant values of its different components. The most striking observation was that the combination of 12 parameters allowed a very significant increase in the diagnostic values of isolated GGT or ALT. The diagnostic value of ALT was better than that of GGT, as assessed by AUROCs in all the different groups. This is surprising as an elevated GGT is generally thought to be a serum marker of steatosis and elevated transaminases to be a marker of NASH. A better association between ALT and steatosis versus GGT and steatosis has also been observed using proton magnetic resonance imaging [32].

The diagnostic values of GGT, ALT, triglycerides, cholesterol, glucose and BMI were expected, because they had been previously associated with steatosis of different origins $[3,29,31]$. Those biomarkers are also associated with insulin resistance and triglyceride deposition in the liver [6]. ApoA1 is highly associated with HDL-cholesterol and a negative association was also expected with steatosis [29]. The advantage of combining biomarkers of steatosis and those more specific for fibrosis such as A2M, haptoglobin and bilirubin is to adjust the predictive values according to the associated stage of fibrosis. In the present study we observed that the grade of steatosis in patients with extensive fibrosis was significantly lower than in patients without extensive fibrosis (data not shown).

Our study has several limitations that must be acknowledged. Firstly, despite the use of prospective cohorts of patients, our study was not a classical prospective study. The validation groups consisted of previously studied groups of patients: groups 1 and 2 were from a prospective randomized trial with a previous publication on steatosis [33], and group 3 was a prospective cohort of patients with alcoholic liver disease from a study which had been published for validation of fibrosis biomarkers [26]. There were three different pathologists but very skilled in these scoring systems and expert in variability studies. The analyses of histological specimens and biochemical markers were performed blindly, and the recommended preanalytical and analytical procedures were respected for most of the components. The analytical variability of cholesterol, triglycerides and glucose should be assessed.

A second limitation was the relatively small number of patients with grade 3 and 4 steatosis. We observed a nonsignificant difference between ST medians, 0.70 for grade 3 versus 0.75 for grade 4 . Due to the small sample size of patients with grade 3-4 steatosis in the validation groups, further studies should be performed in order to determine whether ST could discriminate between patients with marked steatosis (between 30 and 66\%) and those with severe steatosis (over 66\%). Grade 3 and 4 steatosis is more frequent in patients with NAFLD and further studies must be performed in these patients.

In patients with NAFLD, a liver biopsy is more usually obtained for identifying additional features of steatohepatitis (hepatocellular ballooning, lobular inflammation, Mallory's hyaline) which may be associated with and/or predictive for the development of pericellular and/or periportal fibrosis. FT has been already validated for the diagnosis of fibrosis in NAFLD [27] and ALD [26]. Studies on biomarkers of steatohepatitis (NashTest, AshTest) are also in progress (personal communication of Thierry Poynard). Combination of those non-invasive markers should help the physician in the management of NAFLD and ALD.

A third limitation was not having compared prospectively the serum biomarkers with imaging techniques such as ultrasonography $[28,32,34]$ and proton magnetic resonance imaging [35]. In the retrospective analysis of the training population, we observed that ST had a higher diagnostic value than the routine ultrasonography with higher AUROCs. It has been already observed that the sensitivity of ultrasonography is low in obese patients [36] for the diagnosis of steatosis. Proton magnetic resonance imaging is expensive; nevertheless, a validation of ST versus proton magnetic resonance imaging would be quite interesting.

In contrast with the above mentioned limitations, one advantage of the present design was the inclusion of heterogeneous patients in the training group with different causes of chronic liver disease as well as the validation of the diagnostic values in more homogeneous groups. Validation groups 1 and 3 included very homogeneous patients, with chronic hepatitis $\mathrm{C}$ and ALD, respectively. The advantage of validation group 2 was the inclusion of a group of patients clinically and biologically close to a "normal" population, as these patients are sustained virologic responders and had quasi-normal liver function tests. This population offered the unique opportunity of having liver biopsies in subjects with normal profiles not possible, for example, in blood donors. The intra and inter-laboratory variability has been studied for the 6 FT components and those studies should also be performed for cholesterol, triglycerides and glucose. We did not find any significant differences in ST AUROCs according to ethnicity (data not showed) [37].

As discussed for liver fibrosis, it is also possible that the limitations of liver biopsy (sampling error and pathologist concordance) did not allow a perfect area under the curve to be reached [38]. In hepatitis $C$ the ideal gold standard would be at least a $40 \mathrm{~mm}$ length biopsy sample. Bedossa et al. [18] recommend, at least, $25 \mathrm{~mm}$; but the 
coefficient of variation decreases up to $40 \mathrm{~mm}$. In chronic hepatitis C, $18 \%$ of discordance in fibrosis staging has been attributed to liver biopsy failures (mainly due to small sample size) and $2 \%$ to FT (due to hemolysis, inflammation and Gilbert's syndrome) [38]. For liver steatosis, there is also a sampling variability with discordance in $22 \%$ of patients [19]. In the present study, we observed discordance between steatosis assessed by ST and that assessed by biopsy, in $10 \%$ to $21 \%$ according to patient's group. Several discordant cases seem to be attributable to biopsy (false negatives of biopsy) as the quality was poor and, at least, one metabolic risk factor was present. Significant discordance was more often observed in patients with extensive fibrosis. We previously suspected a risk of greater variability in assessing fibrosis when steatosis was present but the inverse could be also true: a greater variability in assessing steatosis in case of cirrhotic or pre-cirrhotic stages [38].

ST is not a perfect diagnostic tool, but has several advantages over other proposed strategies for steatosis management. The 12 components of ST are readily available. FibroTest-ActiTest is now available in several different countries, including the USA (FibroSure ${ }^{\mathrm{rm}}$ ), with a quality charter for laboratories for reducing inter-laboratory variability $[23,30,38,39]$. As demonstrated in the present study, ST allowed the assessment of steatosis in patients with paired biopsy. This could be very useful for the follow-up of patients. This has been validated in HCV patients before and after treatment and should be validated in patients with ALD and NAFLD with paired biopsies.

There is no specific approved treatment for steatosis. Recommendations depend on the cause. There is wide agreement for the cessation of alcohol consumption in heavy drinkers, weight reduction in obese patients, and the treatment of diabetes and hyperlipidemia [1-4]. In patients with chronic hepatitis $\mathrm{C}$ and genotype $3,50 \%$ of the patients treated and who have a sustained virologic response have a disappearance of liver steatosis at the second biopsy [33]. Bellentani et al. [3] recommended that subjects with elevated ALT or GGT should be screened for steatosis using hepatic ultrasonography. They suggested that the demonstration of hepatic steatosis should prompt a reduction of caloric and alcohol intake and follow-up with both ultrasonography and biochemical tests. When clinically indicated, a liver biopsy for assessing the degree of fibrosis and inflammation could be performed.

\section{Conclusion}

According to the low predictive values of ALT, GGT and ultrasonography, as well as the risk and the variability of liver biopsy, the previous strategy could be improved by using better biomarkers of steatosis, such as ST, combined with biomarkers of fibrosis, such as FibroTest-Fibrosure, and with biomarkers of steatohepatitis. The cost will be probably similar to the price of FibroTest-Fibrosure (currently around $100 €$ ) and cheaper than biopsy or proton magnetic resonance imaging. This new strategy will likely reduce the indications of liver biopsy. Prospective studies are needed to confirm those results and to support the general use of this new biomarker.

\section{Methods \\ Study population}

Consecutive patients who were included were those with an available serum sample, a liver biopsy, and a time interval between serum sampling and biopsy of less than three months (Figure 1).

\section{Training group (mixed liver diseases)}

These patients were retrospectively included for this specific analysis, but had been analyzed in previous prospective validation studies of FT between September 2000 and August $2004[23,24,27,38]$. All were patients hospitalized in the of Hepato-Gastroenterology department of Groupe Hospitalier Pitié-Salpêtrière for NAFLD, hepatitis C and B, and ALD.

\section{Validation group one (hepatitis C)}

These patients were retrospectively analyzed from a study of steatosis in patients with chronic hepatitis C [33]. For this purpose, previously non-treated patients of a prospective multicentre randomized trial of pegylated-Interferon and ribavirin were included. The biomarkers and the biopsy results at baseline were used.

\section{Validation group two (former hepatitis $C$, with undetectable $\mathrm{HCV}$ )}

These patients were those from the patients of the same randomized trial [33] who had been "cured" - they had a sustained virologic response, with undetectable HCV RNA, at the end of treatment and 24 weeks after the end of treatment. The biomarkers and the biopsy results performed 24 weeks after the end of treatment were used. This group can be considered to be a validation group of non-viral steatosis because possible viral steatosis had been cured by the treatment [33].

\section{Validation group three (ALD)}

These patients were retrospectively included for this specific analysis but had been prospectively included between 1998 and 2000 in a cohort of alcoholic patients for which one primary endpoint was the identification of biochemical markers. The details of this cohort have been recently published in a validation study of FT [26]. All were patients hospitalized in the Hepato-Gastroenterology Department of Hôpital Antoine Béclère, for complications of alcoholic liver disease. 


\section{Common criteria of non-inclusion}

Non-inclusion criteria included non-available serum, non-available biopsies and biopsy and serum samples which had been collected more than 3 months apart (Figure 1). Patient characteristics are given in Table 1 .

\section{Control groups}

This included a group of, apparently, healthy volunteers who had been previously included in a validation study of FT, in fasting and non-fasting conditions [39]. A group of non-fasting blood donors were also prospectively included.

\section{Histologic analysis}

Common rules were applied to the different groups. Liver biopsy specimens were processed using standard techniques. Patients with viral hepatitis were evaluated for fibrosis and grade of activity according to the METAVIR scoring system, for which reproducibility had previously been established [40]. Patients with ALD and NAFLD were evaluated with modified staging and grading scores [4144 ]. Fibrosis was staged on a scale of 0 to 4 : F0 - no fibrosis; F1 - portal fibrosis or perivenular fibrosis without septa; F2 - few septa; F3 - numerous septa without cirrhosis; and F4 - cirrhosis. Activity (the intensity of necroinflammatory activity mostly based on necrosis) was scored as follows: A0 - no histologic activity; A1 - mild activity; A2 - moderate activity; and A3 - severe activity. Steatosis was scored from 0 to 4 with a four grades scoring system from S0 to S4: S0 - no steatosis; S1 - mild 1 to 5\% (\% of hepatocytes containing visible macrovesicular steatosis); S2 - moderate 6 to 32\%; S3 - marked 33 to 66\%; and S4 - severe 67 to $100 \%$ [33]. The main histological criterion was the presence of steatosis grade 2-4 (between 6 to $100 \%)$. A single pathologist per group, unaware of patient characteristics, analyzed the histological features (Frederic Charlotte for the training group, Zack Goodman for validation groups 1 and 2, and Dominique Capron for validation group 3 ).

\section{Serum biochemical markers - New biomarker of steatosis} A new panel (ST, Biopredictive, Paris, France, patent pending) was constructed in the training group combining the 6 components of the FibroTest-ActiTest (patented artificial intelligence algorithm USPTO 6,631,330) adjusted for age, gender and BMI, plus serum glucose, triglycerides and cholesterol. ST scores of range from zero to 1.00, with higher scores indicating a greater probability of significant lesions. FT and AT (Biopredictive, Paris, France; FibroSURE LabCorp, Burlington, NC, USA) were determined as has been previously published $[23,38,39]$. The published recommended pre-analytical and analytical procedures were used $[23,38,39,45,46]$. In the training and control groups, GGT, ALT, serum glucose, triglycerides, cholesterol, and total bilirubin were measured by Hitachi 917 analyzer or Modular DP analyzers (both Roche Diagnostics Mannheim, Germany) using the manufacturer's reagents. A2M, ApoA1, and haptoglobin were measured using an automatic nephelemeter BNII (Dade Behring; Marburg, Germany). In validation groups 1 and 2, GGT, ALT, serum glucose, triglycerides, cholesterol, and total bilirubin were measured using Hitachi 747 or 911 (Roche Diagnostics, Indianapolis, IN, USA) with the manufacturer's reagents. ApoA1, A2M and haptoglobin were determined in serum samples using an automatic nephelometer BNII (Dade Behring, Marburg, Germany). In validation group 3, ALT, GGT, serum glucose, triglycerides, cholesterol, total bilirubin and haptoglobin were measured by autoanalyzer (Olympus AU 640 Automate) using manufacturer's reagents (Olympus, Rungis, France); $\mathrm{A} 2 \mathrm{M}$ and ApoA1 were measured using an automatic nephelometer (BNII, Dade Behring, Marburg, Germany). All coefficients of variation assays were lower than $10 \%$.

\section{Imaging}

Ultrasonography reports have been retrospectively analyzed for the presence or absence of radiological steatosis in the validation group, blindly to histological and biochemical data.

\section{Statistical analyses}

The primary outcome was grade 2,3 or 4 of steatosis (S2S3S4). The cause of discordance between the presence of S2S3S4 steatosis, as predicted by biochemical markers and biopsy was attributed according to respective risk factors of failure, as previously detailed [38]. Significant discordance was defined as discordance in predicting grades S2S3S4 and a 30\% or greater difference in steatosis percentage, as predicted by ST or as observed in the biopsy sample. Risk factors of ST failure were hemolysis, Gilbert's disease, acute inflammation and extra-hepatic cholestasis. Risk factors of biopsy failure were biopsy size (less than 25 $\mathrm{mm}$ ) and fragmentation (more than one fragment). Failure attributable to biopsy (false negative) was suspected when the biopsy length was less than $15 \mathrm{~mm}$ and fragmented with the additional presence of, at least, one metabolic risk factor.

Statistical analysis used Fisher's exact test, the chi-square test, Student's t-test and the Mann-Whitney test; variance analysis used the Bonferroni all-pair wise and the TukeyKramer multiple-comparison tests to take into account the multiple comparisons, and multiple logistic regression the for multivariate analysis [47]. The diagnostic values of the markers were assessed using sensitivities, specificities, PPVs and NPVs and AUROCs [47]. Corresponding steatosis grades were calculated from median ST scores and 95\% confidence intervals observed in 744 patients and 140 controls. AUROCs were calculated using the empirical non-parametric method according to 
Delong et al. [48] and compared using the method of Zhou et al. [49]. The binomial approach was used only when the sample size population was less than 30 [50]. For all analyses, two-sided statistical tests were used; a Pvalue of 0.05 or less was considered significant. Number Cruncher Statistical Systems 2003 software (NCSS, Kaysville, Utah, USA) was used for all analyses [47].

A sensitivity analysis was also performed for determining the accuracy of the markers for the primary outcomes according to biopsy sample size (less than $20 \mathrm{~mm}$ or more) and to time lapse between serum and biopsy (less than 4 weeks or more).

\section{Competing interests}

Thierry is the inventor of both the FT and the ST, is a consultant and has a capital interest in Biopredictive, the company marketing FibroTest-SteatoTest. Mona Munteanu is employee of Biopredictive, the company marketing FibroTest-SteatoTest.

\section{Authors' contributions}

TP conceived and wrote the manuscript. TP, VR, SN, DT, $\mathrm{JM}, \mathrm{MM}, \mathrm{MM}$ and JA were responsible for the patient drafting, and participated in the coordination of the study. FIB, AA and DM carried out biochemical analysis and drafted the paper. FC and DC were responsible of histological analysis. TP performed the statistical analysis. All authors read and approved the final manuscript.

\section{Acknowledgements}

Thierry Poynard has grants from the Association pour la Recherche sur le Cancer (ARECA) and from the Association de Recherche sur les Maladies Virales Hépatiques.

\section{References}

I. McCullough Al: The clinical features, diagnosis and natural history of nonalcoholic fatty liver disease. Clin Liver Dis 2004, 8:521-33.

2. Clark JM, Brancati FL, Diehl AM: The prevalence and etiology of elevated aminotransferase levels in the United States. Am J Gastroenterol 2003, 98:960-967.

3. Bellentani S, Saccoccio G, Masutti F, Croce LS, Brandi G, Sasso F, Cristanini G, Tiribelli C: Prevalence of and risk factors for hepatic steatosis in Northern Italy. Ann Intern Med 2000, 132:1 | 2-7.

4. Levitsky J, Mailliard ME: Diagnosis and therapy of alcoholic liver disease. Semin Liver Dis 2004, 24:233-47.

5. Day CP: Pathogenesis of steatohepatitis. Best Pract Res Clin Gastroenterol 2002, I 6:663-678.

6. Browning JD, Horton JD: Molecular mediators of hepatic steatosis and liver injury. J Clin Invest 2004, I | 4: | 47- I 52.

7. Wanless IR, Shiota K: The pathogenesis of nonalcoholic steatohepatitis and other fatty liver diseases: a four-step model including the role of lipid release and hepatic venular obstruction in the progression to cirrhosis. Semin Liver Dis 2004, 24:99-106.

8. El-Serag HB, Tran T, Everhart JE: Diabetes increases the risk of chronic liver disease and hepatocellular carcinoma. Gastroenterology 2004, I 26:460-468.

9. Dam-Larsen S, Franzmann M, Andersen IB, Christoffersen P, Jensen LB, Sorensen TI, Becker U, Bendtsen F: Long term prognosis of fatty liver: risk of chronic liver disease and death. Gut 2004, 53:750-755.

10. Sorensen TI, Orholm M, Bentsen KD, Hoybye G, Eghoje K, Christoffersen P: Prospective evaluation of alcohol abuse and alcoholic liver injury in men as predictors of development of cirrhosis. Lancet 1984, 2:24I-244.

II. Teli MR, Day CP, Burt AD, Bennett MK, James OF: Determinants of progression to cirrhosis or fibrosis in pure alcoholic fatty liver. Lancet 1995, 346:987-990.

12. Fabris P, Floreani A, Carlotto A, Giordani MT, Baldo V, Stecca C, Marchioro L, Tramarin A, Bertin T, Negro F, de Lalla F: Alcohol is an important co-factor for both steatosis and fibrosis in Northern Italian patients with chronic hepatitis C. J Hepatol 2004, 41:644-65I.

13. Phillips MJ, Cameron R, Flowers MA, Blendis LM, Greig PD, Wanless I, Sherman M, Superina R, Langer B, Levy GA: Post-transplant recurrent hepatitis $B$ viral liver disease. Viral-burden, steatoviral, and fibroviral hepatitis B. Am J Pathol I992, I 40:| 295-308.

14. Bravo AA, Sheth SG, Chopra S: Liver biopsy. N Engl J Med 200I, 344:495-500.

15. Labayle D, Chaput JC, Albuisson F, Buffet C, Martin E, Etienne JP: Comparison of the histological lesions in tissue specimens taken from the right and left lobe of the liver in alcoholic liver disease. Gastroenterol Clin Biol 1979, 3:235-240.

16. Maharaj B, Maharaj RJ, Leary WP, Cooppan RM, Naran AD, Pirie D, Pudifin DJ: Sampling variability and its influence on the diagnostic yield of percutaneous needle biopsy of the liver. Lancet 1986, I:523-525.

17. Regev A, Berho M, Jeffers LJ, Milikowski C, Molina EG, Pyrsopoulos NT, Feng ZZ, Reddy KR, Schiff ER: Sampling error and intraobserver variation in liver biopsy in patients with chronic HCV infection. Am / Gastroenterol 2002, 97:26/4-2618.

18. Bedossa $P$, Dargère $D$, Paradis $V$ : Sampling variability of liver fibrosis in chronic hepatitis C. Hepatology 2003, 38: I449-57.

19. Ratziu V, Charlotte F, Heurtier A, Gombert S, Giral P, Bruckert E, Grimaldi A, Poynard T, for the LIDO Study Group: Sampling variability of liver biopsy in nonalcoholic fatty liver disease. Gastroenterology 2005, I 28: 1898-1906.

20. Poynard T, Ratziu V, Bedossa P: Appropriateness of liver biopsy. Can J Gastroenterol 2000, I 4:543-548.

21. Cadranel JF, Rufat P, Degos F: Practices of liver biopsy in France: Results of a prospective nationwide survey. For the Group of Epidemiology of the French Association for the Study of the Liver (AFEF). Hepatology 2000, 32:477-48I.

22. Afdhal NH: Biopsy or biomarkers: is there a gold standard for diagnosis of liver fibrosis? Clin Chem 2004, 50: I 299-1 300.

23. Poynard T, Imbert-Bismut F, Munteanu M, Messous D, Myers RP, Thabut D, Ratziu V, Mercadier A, Benhamou Y, Hainque B: Overview of the diagnostic value of biochemical markers of liver fibrosis (FibroTest, HCV FibroSure) and necrosis (ActiTest) in patients with chronic hepatitis C. Comp Hepatol 2004, 3:8.

24. Myers RP, Tainturier MH, Ratziu $\mathrm{V}$, Piton A, Thibault $\mathrm{V}$, Imbert-Bismut F, Messous D, Charlotte F, Di Martino V, Benhamou Y, Poynard $\mathrm{T}$ : Prediction of liver histological lesions with biochemical markers in patients with chronic hepatitis B. J Hepatol 2003, 39:222-230.

25. Callewaert N, Van Vlierberghe H, Van Hecke A, Laroy W, Delanghe J, Contreras R: Noninvasive diagnosis of liver cirrhosis using DNA sequencer-based total serum protein glycomics. Nature Med 2004, 10:1-6.

26. Naveau $S$, Raynard $B$, Ratziu $V$, Abella $A$, Françoise Imbert-Bismut $F$, Messous D, Beuzen F, Capron F, Thabut D, Munteanu M, Chaput JC, Poynard T: The diagnostic value of biomarkers for the prediction of liver fibrosis in patients with chronic alcoholic liver disease. Clin Gastroenterol Hepatol 2005, 3:167-174.

27. Ratziu V, Le Calvez S, Imbert-Bismut F, Messous D, Charlotte F, Bonyhay L, Munteanu M, Poynard T: Diagnostic value of biochemical markers (Fibrotest) for the prediction of liver fibrosis in patients with non-alcoholic fatty liver disease. Hepatology 2003, 38:5IOA.

28. Yao W, Zhao B, Zhao Y, Wang W, Qian G: Ultrasonographic texture analysis of parenchymatous organs by the four-neighborhood-pixels algorithm: clinical experiment. | Ultrasound Med 200I, 20:465-47I. 
29. Marceau P, Biron S, Hould FS, Marceau S, Simard S, Thung SN, Kral JG: Liver pathology and the metabolic syndrome $X$ in severe obesity. J Clin Endocrinol Metab 1999, 84:1513-1517.

30. Papadia FS, Marinari GM, Camerini G, Murelli F, Carlini F, Stabilini C Scopinaro N: Liver damage in severely obese patients: a clinical-biochemical-morphologic study on I,000 liver biopsies. Obes Surg 2004, 14:952-958.

31. Loguercio C, De Simone T, D'Auria MV, de Sio I, Federico A, Tuccillo C, Abbatecola AM, Del Vecchio Blanco C: Italian AISF Clinical Group. Non-alcoholic fatty liver disease: a multicentre clinical study by the Italian Association for the Study of the Liver. Dig Liver Dis 2004, 36:398-405.

32. Mathiesen UL, Franzen LE, Aselius H, Resjo M, Jacobsson L, Foberg $U$, Fryden A, Bodemar G: Increased liver echogenicity at ultrasound examination reflects degree of steatosis but not of fibrosis in asymptomatic patients with mild / moderate abnormalities of liver transaminases. Dig Liver Dis 2002 34:516-22.

33. Poynard T, Ratziu V, McHutchison J, Manns M, Goodman Z, Zeuzem S, Younossi Z, Albrecht J: Effect of treatment with peginterferon or interferon alfa-2b and ribavirin on steatosis in patients infected with hepatitis C. Hepatology 2003, 38:75-85.

34. Mottin CC, Moretto M, Padoin AV, Swarowsky AM, Toneto MG, Glock L, Repetto G: The role of ultrasound in the diagnosis of hepatic steatosis in morbidly obese patients. Obes Surg 2004, 14:635-7.

35. Thomas EL, Hamilton G, Patel N, O'dwyer R, Dore CJ, Goldin RD, Bell JD, Taylor-Robinson SD: Hepatic triglyceride content and its relation to body adiposity: a magnetic resonance imaging and proton magnetic resonance spectroscopy study. Gut 2005, 54: I22-7.

36. Shalhub S, Parsee A, Gallagher SF, Haines KL, Willkomm C, Brantley SG, Pinkas H, Saff-Koche L, Murr MM: The importance of routine liver biopsy in diagnosing nonalcoholic steatohepatitis in bariatric patients. Obes Surg 2004, 14:54-59.

37. Browning JD, Szczepaniak LS, Dobbins R, Nuremberg P, Horton JD, Cohen JC, Grundy SM, Hobbs HH: Prevalence of hepatic steatosis in an urban population in the United States: impact of ethnicity. Hepatology 2004, 40:1387-1395.

38. Poynard T, Munteanu M, Imbert-Bismut F, Charlotte F, Messous D, Dominique Thabut D, Thibaut V, Benhamou Y, Ratziu V: Prospective analysis of discordant results between biochemical markers and biopsy in patients with chronic hepatitis C. Clin Chem 2004, 50:1344-1355.

39. Munteanu M, Messous D, Thabut D, Imbert-Bismut F, Jouys M, Massard J, Piton A, Bonyhay L, Ratziu V, Hainque B, Poynard T: Intraindividual fasting versus postprandial variation of biochemical markers of liver fibrosis (FibroTest) and activity (ActiTest). Comp Hepatol 2004, 3:3.

40. Intraobserver and interobserver variations in liver biopsy interpretation in patients with chronic hepatitis $C$. The French METAVIR Cooperative Study Group. Hepatology I994, 20:15-20.

4I. Bedossa P, Poynard T, Naveau S, Martin ED, Agostini H, Chaput JC: Observer variation in assessment of liver biopsies of alcoholic patients. Alcohol Clin Exp Res 1988, I2:173-178.

42. Poynard T, Mathurin P, Lai CL, Guyader D, Poupon R, Tainturier MH, Myers RP, Muntenau M, Ratziu V, Manns M, Vogel A, Capron F, Chedid A, Bedossa P: A comparison of fibrosis progression in chronic liver diseases. J Hepatol 2003, 38:257-265.

43. Brunt EM, Janney CG, Di Bisceglie AM, Neuschwander-Tetri BA, Bacon BR: Nonalcoholic steatohepatitis: a proposal for grading and staging the histological lesions. Am J Gastroenterol I999, 94:2467-2474

44. Kleiner DE, Brunt EM, Van Natta M, Behling C, Contos MJ, Cummings OW, Ferrell LD, Liu YC, Torbenson MS, Unalp-Arida A, Yeh M, McCullough AJ, Sanyal AJ: Nonalcoholic Steatohepatitis Clinical Research Network. Design and validation of a histological scoring system for nonalcoholic fatty liver disease. Hepatology 2005, 41: | 3|3-|32|.

45. Halfon P, Imbert-Bismut F, Messous D, Antoniotti G, Benchetrit D, Cart-Lamy P, Delaporte G, Doutheau D, Klump T, Sala M, Thibaud D, Trepo E, Thabut D, Myers RP, Poynard T: A prospective assessment of the inter-laboratory variability of biochemical markers of fibrosis (FibroTest) and activity (ActiTest) in patients with chronic liver disease. Comp Hepatol 2002, I:3-7.
46. Imbert-Bismut F, Messous D, Thibaut V, Myers RB, Piton A, Thabut D, Devers L, Hainque B, Mercadier A, Poynard T: Intralaboratory analytical variability of biochemical markers of fibrosis (Fibrotest) and activity (Actitest) and reference ranges in healthy blood donors. Clin Chem Lab Med 2004, 42:323-333.

47. Hintze JL: NCSS 2003 User Guide. Number Cruncher Statistical Systems 2003 Software NCSS Kaysville, Utah: NCSS; 2003.

48. DeLong ER, DeLong DM, Clarke-Pearson DL: Comparing the areas under two or more correlated receiver operating characteristic curves: A nonparametric approach. Biometrics 1988, 44:837-845.

49. Zhou X-H, McClish DK, Obuchowski NA: Statistical Methods in Diagnostic Medicine. New York: John Wiley \& Sons; 2002.

50. McClish DK: Analyzing a Portion of the ROC Curve. Med Decis Making 1989, 9:190-195.
Publish with Biomed Central and every scientist can read your work free of charge

"BioMed Central will be the most significant development for disseminating the results of biomedical research in our lifetime. "

Sir Paul Nurse, Cancer Research UK

Your research papers will be:

- available free of charge to the entire biomedical community

- peer reviewed and published immediately upon acceptance

- cited in PubMed and archived on PubMed Central

- yours - you keep the copyright

Submit your manuscript here:

http://www.biomedcentral.com/info/publishing_adv.asp
BioMedcentral 